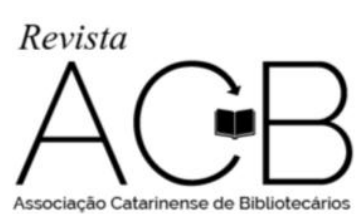

\title{
A GESTÃO DE DOCUMENTOS ARQUIVÍSTICOS DO COLÉGIO PROMOVE DO MUNICÍPIO DE BELO HORIZONTE: ESTUDO DE CASO
}

\section{Alejandro de Campos Pinheiro ${ }^{1}$}

RESUMO: Apresenta a forma de uso e tratamento da documentação arquivística realizado em uma escola da rede privada de Belo Horizonte, o Colégio Promove. Analisa os procedimentos utilizados nas atividades de identificação, avaliação, preservação e eliminação dos documentos escolares produzidos na instituição. Utilizou-se o estudo de caso para compreender a realidade em particular da escola e cujos resultados podem nortear a gestão de documentos escolares de outras instituições. Propõem-se alternativas para a melhoria do processo de gestão documental e como a contratação de um profissional da área de Arquivologia pode contribuir na organização, preservação e acesso aos documentos escolares.

Palavras-chave: Gestão de documentos arquivísticos. Arquivo escolar. Arquivista. Colégio Promove.

\section{INTRODUÇÃO}

A Constituição brasileira (1988) assegura em seu artigo 209 que "O ensino é livre à iniciativa privada, atendidas as seguintes condições: I - cumprimento das normas gerais da educação nacional; II - autorização e avaliação de qualidade pelo Poder Público”.

O princípio da Carta Magna mostra que a criação das unidades de ensino depende exclusivamente de atos de suas mantenedoras. Contudo, para que exista o funcionamento, é necessário o ato formal de autorização.

A lei supracitada autoriza o ensino a livre iniciativa privada, dessa forma, é o primeiro documento que oficializa esta forma de ensino. A partir do instante da criação de uma instituição, seja pública ou privada, ela já começa a gerar documentos e acumulá-los na consecução de algum objetivo. Como qualquer outra organização, a escola também produz documentos com o intuito de registrar as suas ações. Estes documentos são considerados documentos arquivísticos, uma vez que foram produzidos no curso de uma atividade organizada, com uma determinada finalidade, qualquer que seja o suporte, e dotados de organicidade. Os documentos arquivísticos passam por fases (corrente, intermediária e

\footnotetext{
1 Graduação em Biblioteconomia pela Universidade Federal de Minas Gerais (UFMG). Graduação em Arquivologia pela Universidade Federal de Minas Gerais (UFMG). Especialização em Gestão de Bibliotecas Escolares (UFSC). Especialização em andamento em Informática pela Universidade Federal de São Paulo (UNIFESP). E-mail: alejandrocampos29@gmail.com
} 


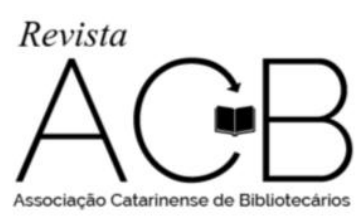

permanente) dentro das instituições são organizados com base na frequência de utilização e os valores a eles atribuídos (primário ou secundário).

Os documentos arquivísticos necessitam de ser organizados, preservados para cumprirem o seu papel. Dessa forma, eles precisam ocupar um local para guarda e depósito para que possam ser acessíveis aos seus usuários. Este espaço denominado arquivo, segundo Paes (2005) apud Santos, Reis (2011 p. 6) significa:

a acumulação ordenada dos documentos, em sua maioria textuais criados por uma instituição ou pessoa, no curso de sua atividade, e preservados para a consecução dos seus objetivos, visando à utilidade que poderão oferecer no futuro.

Segundo Schellenberg (2006, p. 41) “as características essenciais dos arquivos relacionam-se, pois, com as razões pelas quais os documentos vieram a existir”.

A expressiva quantidade de documentos produzidos pelas escolas é significativa e manter a sua organização e preservação para disponibilizar o acesso é de grande relevância, uma vez que registram as atividades peculiares dos indivíduos que nelas passaram como também retratam a memória institucional. São registros de acontecimentos relevantes da vida escolar dos cidadãos que pertencem à sociedade na qual estão inseridas. Segundo Medeiros (2004) apud Silva, Riedlinger, Calderon (2008? p.[1]), os documentos produzidos pelas instituições de ensino "são meios de prova de direito de pessoas ou da administração" e possuem o papel informativo de grande valia para administração pública.

Para reunir toda esta documentação produzida pelas instituições de ensino público e privada, os arquivos escolares são os órgãos responsáveis por manterem esta organização, bem como assegurar a preservação e o acesso aos registros produzidos durante a vida escolar do aluno.

\section{ARQUIVOS ESCOLARES}

O arquivo escolar é responsável pela reunião das mais distintas tipologias documentais que possam ser úteis na composição de uma pasta escolar seja de aluno ou professor. Segundo Medeiros (2003, p. 2) "será conjuntos de documentos produzidos ou recebidos por escolas públicas ou privadas, em decorrência do exercício de suas atividades específicas, qualquer que seja o suporte da informação ou a natureza dos documentos".

Silva, Riedlinger, Calderon (2008? p. 4) afirmam que os arquivos escolares 


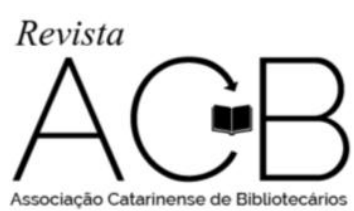

[...] são também fontes de pesquisa porque registram a memória do fazer e pensar pedagógico no cotidiano escolar, além das questões administrativas. O tipo de informação gerado numa escola é bastante específico, refere-se à evolução do número de vagas, ao histórico de reprovações, de evasão escolar, entre outras. Essas informações podem se constituir numa ferramenta importante para a definição de políticas educacionais, seja no âmbito do município ou do Estado.

Além disso, o arquivo escolar tem como função organizar, preservar e disponibilizar os documentos para acesso aos seus usuários, mediante as suas necessidades individuais. A função de preservar o acervo escolar não é de responsabilidade única do arquivo, mas também de todos aqueles profissionais que produzem, manuseiam e utilizam os documentos tramitados até serem acondicionados no arquivo escolar.

Gerenciar arquivos, principalmente os escolares, de forma eficaz é essencial para as instituições de ensino, uma vez que eles armazenam as informações de trajetória de vida das pessoas, relatam a memória da escola e podem influenciar nas tomadas de decisão. Dessa forma é fundamental que a prática arquivística na gestão dos documentos seja adotada para viabilizar a recuperação do documento ou informação.

\section{METODOLOGIA}

Para conhecer a metodologia utilizada da instituição, realizou-se uma entrevista in loco com a secretária do arquivo, uma vez que a mesma é a responsável por gerenciar essa documentação e também por meio da técnica da observação identificou as atividades realizadas no setor da secretaria, local onde são produzidas as peças documentais.

Segundo a secretária são geradas na secretaria do Colégio, as seguintes tipologias documentais: ficha de matrícula, ficha individual, contrato, histórico escolar, diário de classe, declaração de conclusão do ensino médio e declaração de transferência. A partir desta produção, pastas individuais dos alunos em formato físico são confeccionadas para acondicionar os documentos citados anteriormente, com exceção ao diário de classe que fica com o professor até o fim do ano vigente e depois é entregue a secretaria da escola. Neste setor armazenam as pastas dos alunos que permanecem em atividade escolar e quando eles solicitam transferência ou concluem o Ensino Médio, os dossiês dos alunos são recolhidos para a guarda no arquivo escolar que é de fase permanente.

A organização do arquivo é realizada por fundos documentais referentes às unidades do Colégio Promove Savassi; Colégio Promove Mangabeiras; Colégio Promove Pampulha; 


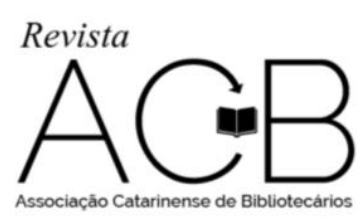

Núcleo Promove de Ensino Médio e Centro de Ensino Supletivo Promove. Segundo Belloto (2008, p. 128) apud Nascimento et al (2011) fundo é o

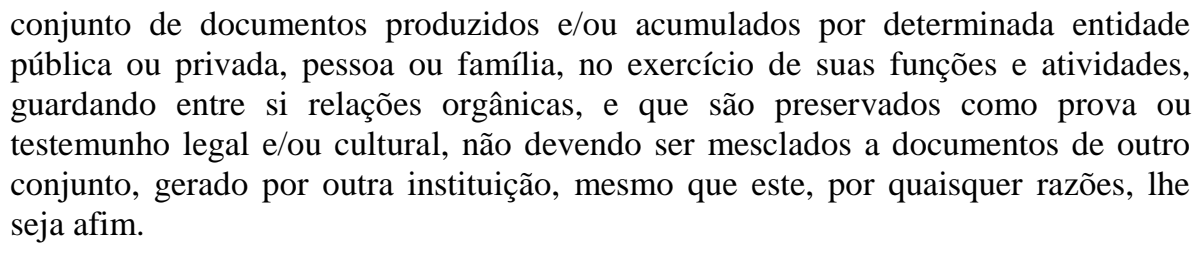

A capa das pastas de papel cartão no qual a documentação dos alunos é reunida, há uma identificação de qual fundo pertence. Apesar dos dossiês de diversos fundos estarem acondicionado em uma mesma caixa tipo arquivo, não há a ocorrência de mistura de documentos, preservando assim, o princípio da proveniência.

A avaliação de documentos é realizada apenas pela secretária responsável pelo arquivo, uma vez que é a única colaboradora da instituição que possui know-how suficiente a respeito de cada documento que constitui o dossiê do aluno. Ela utiliza como amparo em sua avaliação o parecer 1132/97 e instruções normativas emitidas pela secretaria de educação do Estado de Minas Gerais.

Verificou-se que a instituição não possui uma tabela de temporalidade documental referente aos documentos arquivísticos escolares, o que compromete o processo de avaliação de alguns documentos do arquivo. De acordo com Oliveira (2014), os diários de classe são documentos que poderiam ser eliminados após cinco anos, entretanto, não há um embasamento legal que assegura a realização desse procedimento.

Após o cumprimento de sua finalidade no setor de secretaria, os documentos escolares são destinados para o arquivo permanente da instituição, no qual são acondicionados, preservados e microfilmados. Segundo a orientação da Secretaria de Educação do Estado de Minas Gerais (2012), “todo documento onde houver notas, guias de transferências, fichas individuais, histórico escolar, certificado de conclusão de ano, série, etapa ou curso, tudo, enfim, que diz respeito a vida escolar do aluno, deverá ser preservado".

Ainda que constatado uma determinada quantidade de documentos gerados para retratar a vida escolar de cada aluno e o número insuficiente de colaboradores responsáveis pela avaliação da documentação, a constituição de uma comissão de avaliação de documentos seria uma alternativa para contribuir para uma melhor gestão desses documentos. Porém, não foi identificado mobilização por parte da instituição ou de colaboradores que possuem 


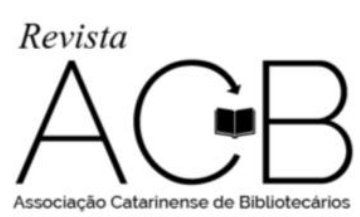

conhecimento específico sobre os documentos escolares e interesse em participar dessa comissão.

\title{
4 GESTÃO DE DOCUMENTOS ARQUIVÍSTICOS NO COLÉGIO PROMOVE
}

Segundo a Lei federal 8.159, de 8 de janeiro de 1991, considera-se gestão de documentos "o conjunto de procedimentos e operações técnicas referentes à sua produção, tramitação, uso, avaliação e arquivamento em fase corrente e intermediária, visando a sua eliminação ou recolhimento para guarda permanente".

A implantação da gestão de documentos é fundamental para que as instituições possam organizar, recuperar e disponibilizar em tempo hábil a documentação solicitada. A utilização deste procedimento contribui na racionalização do tempo durante o processo de busca e recuperação da informação; evita a produção desnecessária de documentos e a formação de massa acumulada documental; otimização do espaço; redução de custos e preservação da memória institucional.

\begin{abstract}
Instituir uma política dessa natureza nas escolas públicas [ou privadas] pode contribuir para garantir que atividades sejam documentadas adequadamente; que documentos inúteis e transitórios não sejam reunidos a documentos de valor permanente; a melhor organização desses documentos, caso atinjam a fase permanente; não sejam eliminados documentos de valor permanente; e ainda, que seja definida, de forma criteriosa, a parcela de documentos que devem constituir o patrimônio arquivístico de um país, estado ou instituição, tornando o processo de recuperação de informação mais ágil e eficiente. (SILVA, RIEDLINGER, CALDERON, 2008? p. 7)
\end{abstract}

O Colégio Promove, localizado na região da Pampulha, na cidade de Belo Horizonte oferta ensino para a Educação Infantil até o Ensino Médio. Composta atualmente, por 389 alunos distribuídos entre os períodos da manhã e tarde conta com 40 professores e 65 colaboradores que contribuem juntos em atender a atividade final da instituição: oferecer um ensino de qualidade. Ao final de 2006, o Colégio Promove uniu à Associação Educativa do Brasil (SOEBRAS), instituição presente em 28 Estados do País formando assim um grande complexo educacional.

$\mathrm{O}$ arquivo escolar do Colégio Promove é centralizado, pois armazena documentos de todas as unidades da instituição existentes desde 1971 (Colégio Promove Savassi; Colégio Promove Mangabeiras; Colégio Promove Pampulha; Núcleo Promove de Ensino Médio; Centro de Ensino Supletivo Promove). Ele ocupou três endereços distintos desde sua criação 


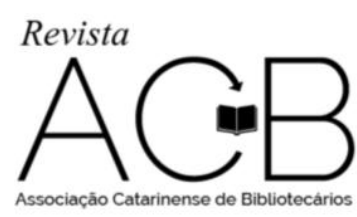

(Rua São Paulo; rua Gonçalves Dias; rua Santa Rita Durão; avenida Bandeirantes, todos localizados em Belo Horizonte) e atualmente está situado no Colégio Promove Pampulha.

O Arquivo Escolar divide o seu espaço com o Arquivo Jurídico da Associação Educativa do Brasil (SOEBRAS). A sala que abriga os dois arquivos é de 48 metros quadrados, dos quais 16 metros quadrados são destinados para o Arquivo Escolar e os 32 metros quadrados restantes são destinados para o Arquivo Jurídico.

No Arquivo Escolar do Colégio Promove consta os dossiês dos alunos que estudaram na instituição, desde 1971 e dos professores que lá exercem as suas atividades. Eles são colocados em pastas de papel cartão dentro de caixas tipo arquivo de papelão que contabilizam 600 caixas distribuídas sobre oito estantes de aço totalizando 7.500 metros lineares de documentos. As caixas são identificadas por números sequenciais, e nas pastas de papel cartão são colocados os dossiês, em ordem numérica (data de entrada do dossiê no arquivo escolar) com a finalidade de facilitar a localização e acesso.

Figura. 1- Arquivo escolar Colégio Promove: vista lateral

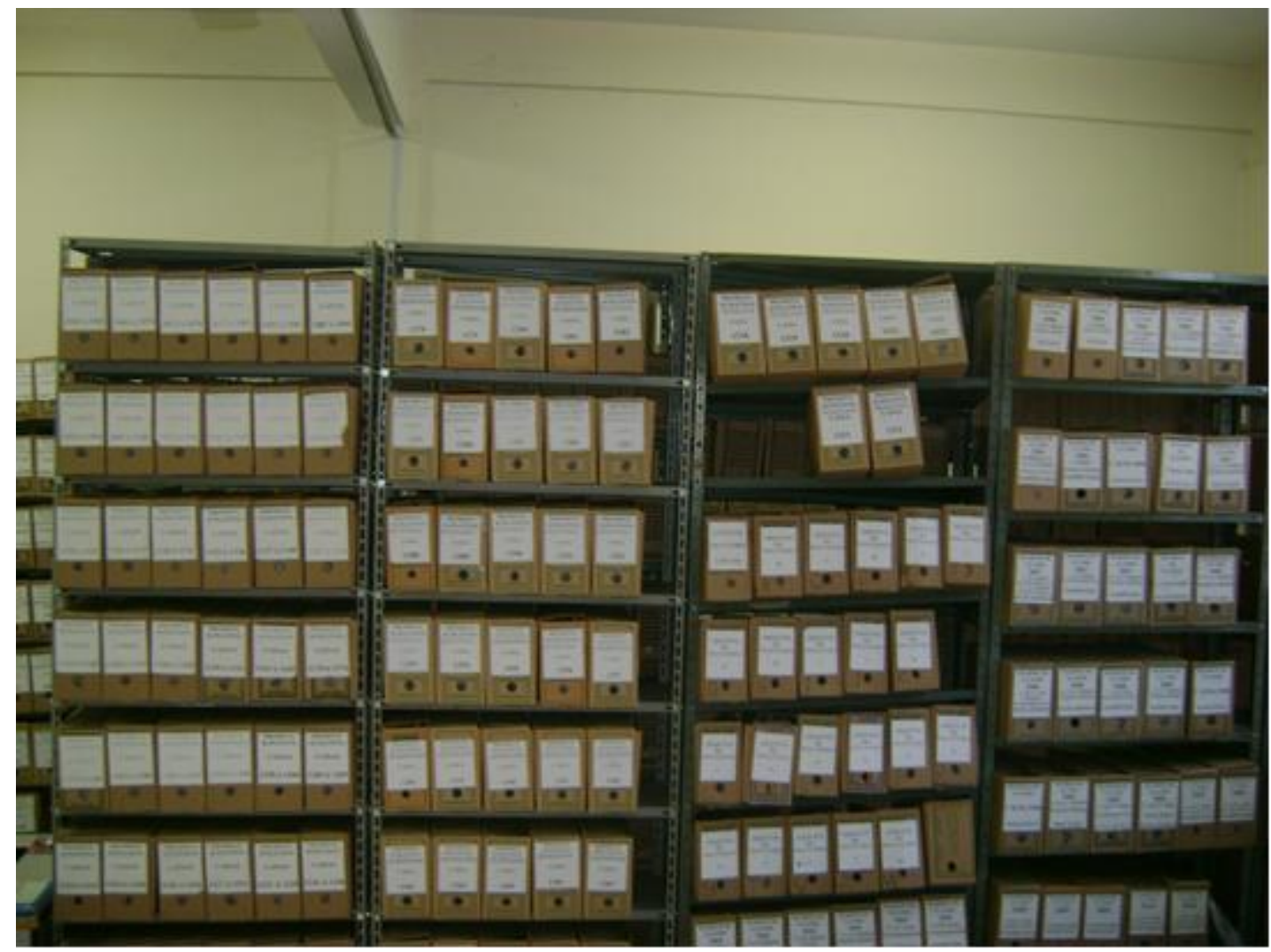

Fonte: Pesquisa. 


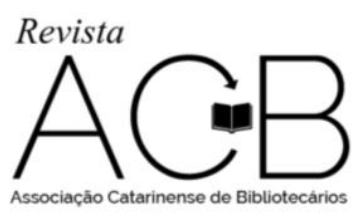

Conforme mencionado anteriormente, a mudança de espaço físico pelas quais passou o arquivo escolar do Colégio Promove resultou na perda de diversos documentos. Entretanto, como o arquivo realizava o processo de microfilmagem nenhum usuário ficou sem o documento solicitado. Atualmente no arquivo se encontra, uma estante de aço onde estão acondicionados 284 microfilmes do colégio nos períodos de 1971 a 2006. A partir de 2007, o processo de microfilmagem foi interrompido e desde então, o arquivo escolar do Colégio Promove não utilizou nenhuma outra mídia para back up dos documentos físicos.

Por volta de 1999, um técnico de informática adaptou os campos do programa Microsoft Access e formulou um banco de dados, que permitiu realizar a descrição dos documentos físicos e dos microfilmes. Por meio dele, foi possível estabelecer uma organização, localização e acesso aos documentos escolares. A recuperação dos documentos referente à vida escolar do estudante é feita pelo o nome do aluno ou filiação.

Figura 2 - Banco de dados do Arquivo escolar do Colégio Promove

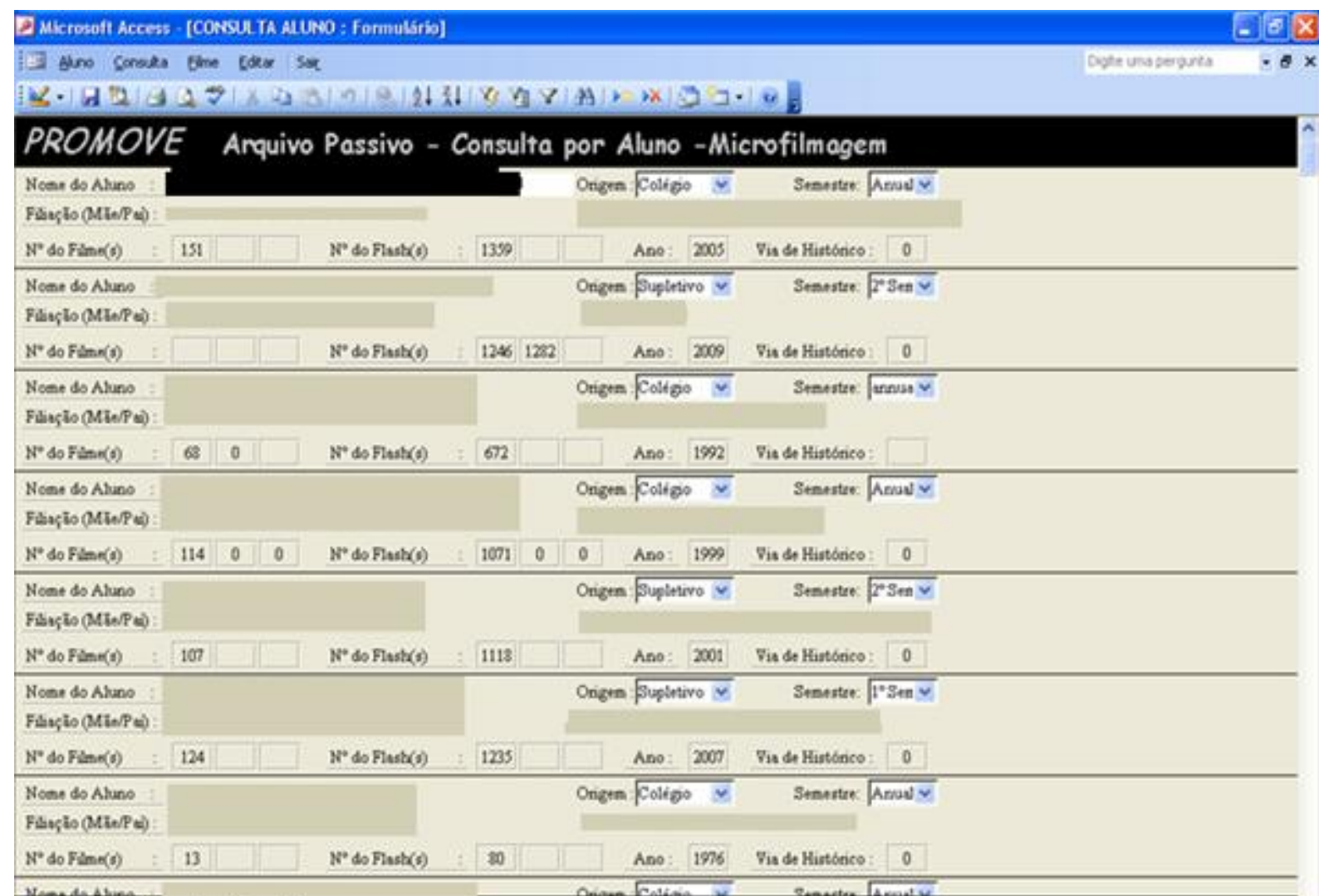

H.7. Snir A Localizar Aluno

Fonte: Pesquisa. 


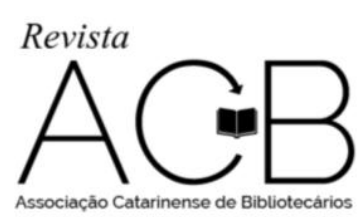

Caso o programa esteja indisponível para consulta, a secretária responsável pelo arquivo escolar possui uma pasta catálogo, no qual estão relacionados os nomes dos alunos e as pastas correspondentes em que se encontram acondicionados os dossiês.

Percebe-se que o banco de dados contribui na organização do arquivo, uma vez que por meio dele é possível recuperar as informações contidas nos documentos. Entretanto, os campos utilizados para este fim restringem as formas de busca pelos dossiês ou peças documentais. Dessa forma, conforme relata Tessitore (2011, p. 164) "toda classificação/ordenação é limitada e esses limites só podem ser ultrapassados através da descrição, o "elo suficiente e necessário" entre o pesquisador e o documento".

A autora supracitada salienta que

\begin{abstract}
a descrição é um conjunto de procedimentos que, levando em conta os elementos formais e de conteúdo do documento, possibilitam a elaboração de instrumentos de pesquisa. Os instrumentos, produtos do processo descritivo, devem fornecer aos usuários do arquivo os elementos de que necessitam para a consulta que desejam realizar, e neles deve ser baseado o atendimento ao público. A descrição arquivística é múltipla, ou seja, ocupa-se do acervo em seus vários níveis, do fundo à peça documental. (TESSITORE, 2011, p. 164)
\end{abstract}

Dessa forma, para que seja ampliada a recuperação dos documentos é necessária que a descrição faça parte das rotinas do arquivo, atividade esta que não ocorre devido à ausência de conhecimento especializado da responsável pelo arquivo escolar da instituição.

\title{
5 INSTRUMENTOS DE GESTÃO DE DOCUMENTOS
}

Para que uma instituição possua uma boa gestão documental é essencial à identificação dos documentos que serão transferidos, recolhidos ou eliminados. Para isso acontecer, os documentos arquivísticos são inicialmente avaliados segundo os seus valores para que posteriormente sejam definidos os seus prazos de guarda. A avaliação dos documentos se fundamenta na legislação em vigor ou ocorre por meio de um ato discricionário de cada instituição.

A partir do processo de avaliação é criada a Tabela de Temporalidade de Destinação que consiste em um "Instrumento de destinação, aprovado por autoridade competente, que determina prazos e condições de guarda tendo em vista a transferência, o recolhimento, o descarte ou a eliminação de documentos". (DICIONÁRIO DE TERMINOLOGIA ARQUIVÍSTICA, 2005, p. 159). Outro instrumento que contribui na gestão documental é o 


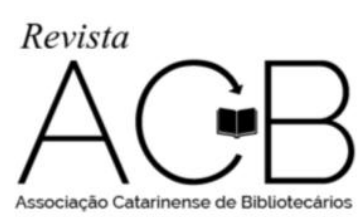

Plano de Classificação, que objetiva facultar o arquivamento correto dos documentos em classes.

A ausência desses instrumentos impede que uma melhor gestão de documentos seja realizada, uma vez que possibilita o acúmulo de documentos e formulários que poderiam ter outra destinação. Para isso é importante que autoridades competentes, como diretores de escolas, secretarias municipais e estaduais de Educação sejam esclarecidas e informadas quanto à existência desses instrumentos, inclusive o uso da legislação para fundamentar na construção dos mesmos.

\section{INFRAESTRUTURA}

Verifica-se que a infraestrutura do arquivo escolar do Colégio Promove não segue alguns parâmetros do CONARQ apud BARRETO et al. (2009), que precisam ser considerados, como os descritos a seguir:

O formato dos documentos, o volume do acervo e sua taxa de crescimento; A localização do terreno, as condições climáticas e os diversos aspectos funcionais que devem ser atendidos no projeto arquitetônico;

As áreas destinadas aos depósitos, sem contar as de atendimento ao público e as de trabalho técnico, devem seguir especificações de resistência estrutural, compartimentação e pé direito, além de iluminação, ventilação e segurança contra sinistros;

As estruturas do depósito podem ser de concreto ou de armação metálica autoportante; É recomendável dividir diversas áreas de depósito, separando-as entre si por paredes, pisos e portas especiais de modo que cada área corresponda a 200 metros quadrados, com capacidade para um pouco mais de mil metros lineares de prateleiras em estantes não compactas (em estantes compactas, este número pode dobrar). A fim de se evitar a umidade, falta de circulação do ar e a proliferação de microrganismos e insetos, as estantes devem estar afastadas $0,30 \mathrm{~m}$ das paredes, afastadas, $0,10 \mathrm{~m}$ do piso e possuir vão livre acima da última prateleira de $0,30 \mathrm{~m}$ até, no máximo, $0,50 \mathrm{~m}$;

Tubulações hidráulicas não devem margear os depósitos;

Rotinas de limpeza devem ser asseguradas para impedir a proliferação de microrganismos e insetos.

Na verdade, presencia-se uma série de inconsistências referentes aos aspectos físicos. As mesas de trabalho são instaladas dentro da sala. Não há uma política de preservação de documentos, uma vez que não há controle de umidade, ventilação e temperatura. A iluminação é realizada com lâmpadas fluorescentes, não há cortinas persianas nas janelas, o que permite o aumento de incidência de raios solares diretamente nos documentos contribuindo assim para uma deterioração mais agressiva de todo o acervo. 


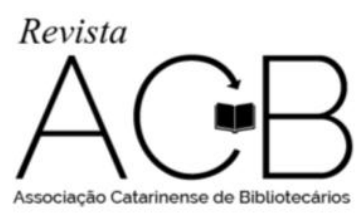

A porta não é corta-fogo, e sim de madeira. A máquina de microfilmagem fica exposta a incidência de raios solares, o que prejudica o seu funcionamento e a visualização dos microfilmes. O ambiente é vulnerável quanto à segurança, organização e preservação dos documentos devido ao fato de a chave ser única para ambos os arquivos, de qualquer funcionário da instituição ter acesso à chave do setor.

Figura 3 - Arquivo escolar Colégio Promove: vista frontal

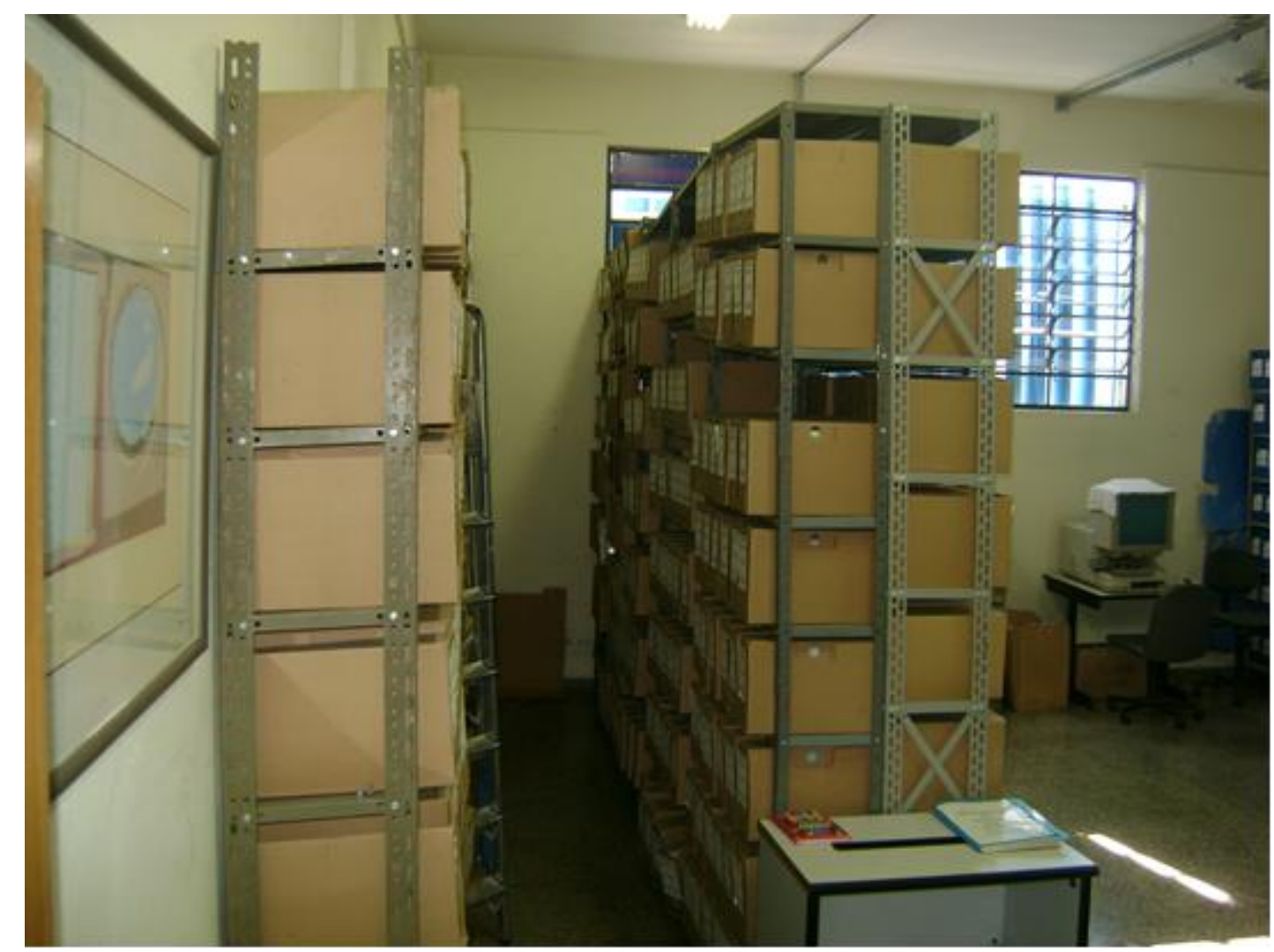

Fonte: pesquisa.

\section{ARQUIVO ESCOLAR COMO MEMÓRIA INSTITUCIONAL}

A História da Educação, em seu campo reflexivo, tem se esforçado no aspecto de preservação e organização dos arquivos escolares, compreendidos como locais de memória, essenciais para o estudo dos processos de escolarização, da cultura escolar, entre outros. (GONÇALVES, 2008, p. 72)

Justino Magalhães (1998, p. 61), apud Gonçalves (2008, p. 76) exalta que o arquivo escolar é fonte fundamental, já que o percurso da instituição é estabelecido "da(s) memória(s) para o arquivo e do arquivo para a memória" buscando-se integrar uma análise multidimensional desse itinerário. 


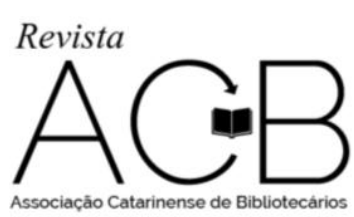

Vidal (2005, p. 19), baseada nas reflexões de Pierre Nora (1993), destaca "os arquivos como lugares de memória, lugares duplos enquanto locais de guarda de seus acervos, mas, ao mesmo tempo, "constantemente abertos a novas leituras acerca do passado e o presente"”.

Diante destes aspectos verifica-se que o arquivo escolar pode ser considerado o lugar de memória da instituição, ao acondicionar documentos da trajetória de vida do aluno na escola. Cadernos, fotografias, moedas, cartilhas, discos são algumas espécies documentais que podem ser encontradas no arquivo e que representam a história da escola.

Por meio de investigações em um arquivo escolar é possível identificar como, quando e por que foi criada a escola; quais indivíduos por ela passaram; quais alterações de infraestrutura incidiram ao longo de sua existência; a oferta de cursos no decorrer dos anos ou décadas; as distintas formas de organização de currículos e horários; os métodos e materiais pedagógicos que utilizou e a importância que teve e possui para a comunidade. Esses são alguns aspectos que poderiam ser explorados para um maior conhecimento sobre a história da escola.

\begin{abstract}
A literatura vem demonstrando a importância em associar alunos, professores e funcionários à organização e manutenção dos acervos escolares, na certeza de que a perenidade dessas iniciativas repousa no seu acolhimento pelo efetivo da escola. Despontam, assim, argumentos em defesa da necessidade de integrar o funcionamento da secretaria à prática do arquivo permanente, gerando instrumentos de trabalho próprios ao universo documental da escola; e sobre a relevância em tornar o arquivo vivo, seja pela participação de alunos e professores na atividade de organização e guarda do acervo, seja pelo uso de alguns documentos escolares em sala de aula. (VIDAL, 2005, p. 72)
\end{abstract}

Vidal (2005, p. 2) corrobora as ideias acima ao destacar que surgem temas para pesquisa como "a constituição do currículo, a formação das disciplinas escolares, o cotidiano institucional, o exercício diário de professores e professoras, alunos e alunas, a materialidade da escola e os recursos metodológicos".

Embora diversos autores demonstrem em seus estudos o arquivo escolar como fonte de memória institucional, o Colégio Promove destoa um pouco deste cenário. Das pesquisas realizadas em demais arquivos, no arquivo escolar da instituição não consta em seu acervo a presença de peças documentais produzidas pelos alunos, apenas aquelas já confeccionadas no setor de secretaria. Assim, em especial, este arquivo possui pouco vínculo com a instituição no aspecto histórico, representando minimamente a memória escolar. 


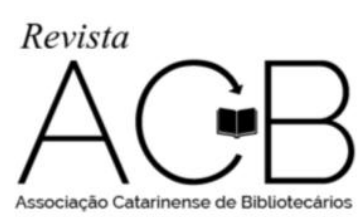

\section{ATUAÇÃO DO PROFISSIONAL DA ARQUIVOLOGIA NO ARQUIVO ESCOLAR}

Com o intuito de gerenciar melhor a rotina administrativa e implantar as práticas arquivísticas, a atuação de um profissional graduado em Arquivologia é relevante para a instituição, uma vez que há a necessidade de desenvolvimento de uma série de políticas, instrumentos que seriam essenciais para a organização, preservação e ao acesso aos documentos.

Considera-se que para garantir a durabilidade dos documentos e das informações neles registradas, o arquivista por meio do seu conhecimento empírico deve realizar intervenções de modo a prorrogar o prazo de vida dos suportes documentais.

A construção de Tabela de Temporalidade Documental e Destinação e o Plano de Classificação são instrumentos fundamentais para que a gestão documental ocorra em sua plenitude, de modo que os documentos avaliados sejam recolhidos ou eliminados a partir do momento em que cumpriu com a sua finalidade. Para isso é necessário que haja no quadro de funcionários, um arquivista, que juntamente com uma comissão de avaliação de documentos possam juntos desenvolver estas ferramentas.

A aquisição de novo mobiliário, mudança de layout e a forma de acondicionamento dos dossiês dos alunos e professores precisam ser alterados com o objetivo de otimizar o espaço e contribuir na conservação dos documentos armazenados no arquivo escolar. $\mathrm{O}$ arquivista com uma visão estratégica e dinâmica é o profissional adequado para que a organização do ambiente possibilite a preservação e o acesso aos documentos solicitados.

$\mathrm{O}$ arquivista com o seu conhecimento adquirido e sua experiência contribuirá na realização de uma melhor gestão de documentos no arquivo escolar do Colégio Promove e fortalecerá ainda mais esta área que possui pouca atenção e prestígio pelas instituições e a sociedade.

\section{CONSIDERAÇÕES FINAIS}

A gestão documental é o procedimento inicial de organização de um arquivo para que ele cumpra com a sua finalidade: oferecer acesso aos documentos e/ou informação. Compreender a produção, uso, tramitação e destinação dos documentos é essencial para contribuir com que o arquivo escolar do Colégio Promove desempenhe melhor as suas atividades. 


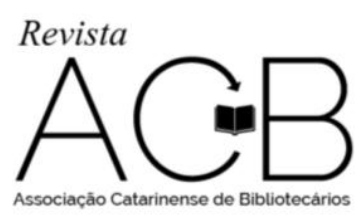

Percebe-se que apesar do arquivo escolar da instituição armazenar documentos de valores permanentes há pouca preocupação na preservação dos mesmos, uma vez que a sala que os acondiciona é inadequado devido à incidência de raios solares, oscilação de temperatura, frestas na parede o que compromete a sua durabilidade.

A divisão da sala com outro tipo de arquivo, o acesso à chave do arquivo a qualquer funcionário e a ausência de políticas de preservação de documentos, prevenção a sinistros comprometem a sua organização deixando-o vulnerável a perda ou guarda errônea dos documentos.

Visto que o arquivo escolar é responsável pela guarda de documentos que relatam a trajetória de vida dos alunos e professores, o mesmo precisa ocupar um espaço com infraestrutura adequada, pois cabe a ele emitir o histórico escolar, documento que segundo o Parecer 1.132/97 é de responsabilidade única da instituição de ensino.

Ausência de instrumentos de gestão documental como a tabela de temporalidade documental e o plano de classificação é fundamental para que haja uma eficiente organização dos documentos durante todo o seu trâmite, uma vez que são eles que delimitam os prazos de guarda e a destinação final do documento: guarda ou eliminação. Segundo Oliveira (2014) os diários de classe poderiam ser eliminados após 5 anos, mas conforme ressaltado por ela, não há uma resolução, parecer ou lei que fornece segurança adequada para que seja realizada tal procedimento. Dessa forma, a criação destes instrumentos forneceria um direcionamento adequado para estes diários.

$\mathrm{O}$ arquivo escolar do Colégio Promove apresenta poucas características que refletem a memória institucional. A sua organização é voltada a uma arquivística integrada, no qual consiste no tratamento da informação desde sua origem até o seu destino final. $\mathrm{O}$ arquivo permanente está diretamente associado ao arquivo corrente e a documentação que ele acumula é composta por ficha de matrícula, ficha individual, contrato, histórico escolar, diário de classe, declaração de conclusão do ensino médio e declaração de transferência. Estas tipologias não apresentam valor significativo do aspecto de representatividade de memória institucional.

O arquivista possui um mercado amplo de atuação e o arquivo escolar é mais um espaço propício para que ele desempenhe as suas atividades profissionais. Ele deve ficar atento para este nicho, pois, infelizmente percebe-se o descaso de muitas instituições de ensino em relação aos seus arquivos. O arquivo escolar do Colégio Promove mesmo com a 


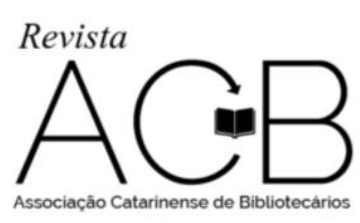

ausência de um profissional qualificado tenta cumprir com a sua finalidade de disponibilizar acesso à informação desejada.

\section{REFERÊNCIAS}

BRASIL. Constituição. Constituição da República Federativa do Brasil. Brasília, DF. Senado, 1988. Disponível em:

<http://www.planalto.gov.br/ccivil_03/constituicao/constituicao.htm>. Acesso em: 22 mar. 2014.

Lei n. 8.159 de 8 de janeiro de 1991. Dispõe sobre a política nacional de arquivos públicos e privados e dá outras providências. Diário Oficial da União. Brasília, 09 jan. 1991. Disponível em: <http://www.planalto.gov.br/ccivil_03/leis/L8159.htm>. Acesso em: 1 maio 2014.

CONARQ. Conselho Nacional de Arquivos. Disponível em: <http://www.conarq.arquivonaci onal.gov.br/cgi/cgilua.exe/sys/start.htm>. Acesso em: 22 mar. 2014 apud BARRETO et al. Diagnóstico dos arquivos da justiça do trabalho: relatório da situação atual e recomendações. Brasília: [s.n.], 2009.

GONÇALVES, Nadia Gaiofatto. O arquivo histórico escolar, a Universidade e a escola: diálogos possíveis. Caderno de Educação: FaE/PPGE/UFPel, Pelotas, n. 31, jul./dez. 2008. Disponível em: <http://www2.ufpel.edu.br/fae/caduc/downloads/n31/04.pdf > . Acesso em: 11 maio 2014.

MAGALHÃES, Justino. Um apontamento metodológico sobre a história das instituições educativas. In: SOUSA, Cynthia P. e CATANI, Denice B. (orgs.) Práticas educativas, culturas escolares, profissão docente. São Paulo: Escrituras, 1998, p.51-69 apud GONÇALVES, Nadia Gaiofatto. O arquivo histórico escolar, a Universidade e a escola: diálogos possíveis. Caderno de Educação: FaE/PPGE/UFPel, Pelotas, n. 31, jul./dez. 2008. Disponível em: 〈http://www2.ufpel.edu.br/fae/caduc/downloads/n31/04.pdf $>$. Acesso em: 11 maio 2014.

MEDEIROS, Ruy Hermann Araújo. Arquivos escolares - breve introdução ao seu conhecimento. In: COLÓQUIO DO MUSEU PEDAGÓGICO, 3., 2003, Vitória da Conquista. Palestra ... Vitória da Conquista: [s.n.], 2003 p. [1-11]. Disponível em:

<http://www.histedbr.fae.unicamp.br/navegando/artigos_pdf/Ruy_Medeiros2_artigo.pdf $>$. Acesso em: 1 maio 2014.

MINAS GERAIS. Conselho Estadual de Educação. Parecer n.1132/97. Dispõe sobre a Educação Básica, nos termos da Lei 9.394/96. Disponível em: <http://www.betim.mg.gov.br/ARQUIVOS_ANEXO/parecer_1132_97;07242613;20070227. pdf>. Acesso em: 12 maio 2014.

MINAS GERAIS. Secretaria de Estado de Educação. Oficio circular SB/SOE/DRFE n.5/2012. Orienta as superintendências regionais de ensino/SER sobre recolhimento de arquivo e instituição escolar devido a paralisação ou encerramento de atividades escolares. 


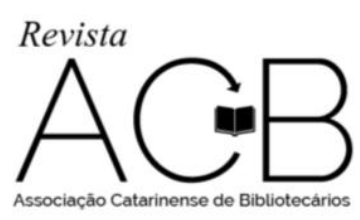

NASCIMENTO, Adalson de Oliveira; CHAMON, Carla Simone; ARAUJO, A. N.; MELO, B. M. W.; TEDESCHI, D. M. R.; SOUZA, I. A.; RIBEIRO, J. L. M.; MARTINS, N. R. Teoria e prática arquivística na organização do acervo da Escola Técnica Federal de Minas Gerais (1943-1978). In: CHAMON, Carla Simone; NASCIMENTO, Adalson de Oliveira. Inventário do acervo da Escola de Aprendizes Artífices de Minas Gerais. Belo Horizonte: CEFET-MG, 2011.

OLIVEIRA, Virgínia Lúcia de. Belo Horizonte, Brasil, 29 abr. 2014. Entrevista concedida a Alejandro de Campos Pinheiro.

PAES, Marilena Leite. Arquivo: teoria e pratica. 3. ed. rev. e ampl. Rio de Janeiro: Editora da Fundação Getulio Vargas, 1997. 225 p.

SANTOS, João Tiago; REIS, Leonardo. Arquivologia facilitada: teoria e questões comentadas. Rio de Janeiro: Elsevier, 2011.

SCHELLENBERG, T.R. Arquivos modernos: teoria e prática. 6. ed. Rio de Janeiro: Ed. Da FGV, 2006. 345 p.

SILVA, Claudecir Almeida; RIEDLINGER, Marcia Aparecida; CALDERON, Wilmara R. A gestão da documentação escolar: o caso do colégio Marcelino Champagnat.

TESSITORE, Viviane. Arquivos e centros de documentação: um perfil. In: ALMEIDA, Juniele Rabelo de; ROVAI, Marta Gouveia de Oliveira. Introdução à história pública. São Paulo: Letra e Voz, 2011.

VIDAL, Diana Gonçalves. Apresentação do dossiê Arquivos Escolares: desafios à prática e à pesquisa em história da educação. Revista Brasileira de História da Educação, v.5, n. 2, [10], jul./dez. 2005. Disponível em:

<http://www.rbhe.sbhe.org.br/index.php/rbhe/article/view/167/176>. Acesso em: 11 maio 2014.

VIDAL, Diana Gonçalves. Cultura e prática escolares: uma reflexão sobre documentos e arquivos escolares. In: SOUZA, Rosa Fátima e VALDEMARIN, Vera T. (Orgs.) A cultura escolar em debate: questões conceituais, metodológicas e desafios para a pesquisa.

Campinas, SP: autores Associados, 2005b.

\title{
ARCHIVISTIC DOCUMENT MANAGEMENT OF PROMOVE SCHOOL IN BELO HORIZONTE: CASE STUDY
}

\begin{abstract}
This article presents how is the use and treatment of archivistic documents carried in a private school in Belo Horizonte, the Promove School. Analyzes the procedures used in the identification, evaluation, preservation and disposal of school documents produced in institution activities. Proposes alternatives that can contribute to the improvement of document process management and how to employ a professional in the field of Archivology can contribute to the organization, preservation and access to schools documents.
\end{abstract}

Keywords: Records management . School archive. Archivist. Promove School. 